\title{
Lipid-based liquid crystalline nanoparticles as oral drug delivery vehicles for poorly water-soluble drugs: cellular interaction and in vivo absorption
}

This article was published in the following Dove Press journal:

International Journal of Nanomedicine

12 July 2012

Number of times this article has been viewed

\author{
Ni Zeng ${ }^{1,3, *}$ \\ Xiaoling $\mathrm{GaO}^{2, *}$ \\ Quanyin $\mathrm{Hu}^{\prime}$ \\ Qingxiang Song² \\ Huimin Xia' \\ Zhongyang Liu' \\ Guangzhi Gu' \\ Mengyin Jiang ${ }^{1,4}$ \\ Zhiqing Pang' \\ Hongzhuan Chen ${ }^{2}$ \\ Jun Chen' \\ Liang Fang ${ }^{3}$
}

'Key Laboratory of Smart Drug Delivery, Ministry of Education and

PLA, School of Pharmacy, Fudan

University, Shanghai, ${ }^{2}$ Department of

Pharmacology, Institute of Medical

Sciences, Shanghai Jiaotong University

School of Medicine, Shanghai,

${ }^{3}$ Department of Pharmaceutical

Science, School of Pharmacy, Shenyang

Pharmaceutical University, Shenyang,

Liaoning, ${ }^{4}$ School of Pharmacy,

Shandong University of Traditional

Chinese Medicine, Jinan, Shandong

People's Republic of China

*These authors contributed equally to this work

Correspondence: Jun Chen

Key Laboratory of Smart Drug Delivery,

Ministry of Education and PLA,

School of Pharmacy, Fudan University,

Lane 826, Zhangheng Road,

Shanghai 20I203,

People's Republic of China

Tel +862151980066

Fax +86 21 51980069

Email chenjun@fudan.edu.cn
Background: Lipid-based liquid crystalline nanoparticles (LCNPs) have attracted growing interest as novel drug-delivery systems for improving the bioavailability of both hydrophilic and hydrophobic drugs. However, their cellular interaction and in vivo behavior have not been fully developed and characterized.

Methods: In this study, self-assembled LCNPs prepared from soy phosphatidylcholine and glycerol dioleate were developed as a platform for oral delivery of paclitaxel. The particle size of empty LCNPs and paclitaxel-loaded LCNPs was around $80 \mathrm{~nm}$. The phase behavior of the liquid crystalline matrix was characterized using crossed polarized light microscopy and small-angle $\mathrm{X}$-ray scattering, and showed both reversed cubic and hexagonal phase in the liquid crystalline matrix. Transmission electron microscopy and cryofield emission scanning electron microscopy analysis revealed an inner winding water channel in LCNPs and a "ball-like"/"hexagonal" morphology.

Results: Cellular uptake of LCNPs in Caco-2 cells was found to be concentration-dependent and time-dependent, with involvement of both clathrin and caveolae/lipid raft-mediated endocytosis. Under confocal laser scanning microscopy, soy phosphatidylcholine was observed to segregate from the internalized LCNPs and to fuse with the cell membrane. An in vivo pharmacokinetic study showed that the oral bioavailability of paclitaxel-loaded LCNPs (13.16\%) was 2.1 times that of $\operatorname{Taxol}^{\circledR}$ (the commercial formulation of paclitaxel, 6.39\%).

Conclusion: The findings of this study suggest that this LCNP delivery system may be a promising candidate for improving the oral bioavailability of poorly water-soluble agents.

Keywords: soy phosphatidylcholine, glycerol dioleate, liquid crystalline nanoparticles, paclitaxel, cellular interaction

\section{Background}

Delivery of poorly water-soluble drugs with clinically acceptable bioavailability is still one of the major challenges in pharmaceutical science. Nearly $40 \%$ of new drug candidates have low water solubility, leading to decreased absorption in the gastrointestinal lumen, resulting in poor oral bioavailability. ${ }^{1}$ Paclitaxel is an example of this problem. As a class IV agent in the biopharmaceutics classification system, ${ }^{2}$ the clinical application of paclitaxel is greatly hindered by poor water solubility $(<1 \mathrm{mg} / \mathrm{L})$ and low permeability across the intestinal barrier. ${ }^{3}$ Paclitaxel is usually administered intravenously as a concentrated solution under the trade name Taxol ${ }^{\circledR}$, which contains paclitaxel $6 \mathrm{mg} / \mathrm{mL}$ in a mixed solvent composed of Cremophor ${ }^{\circledR} \mathrm{EL}$ and ethanol $(1: 1, v / v)$. However, Cremophor EL is not generally well tolerated and frequently causes side effects, including hypersensitivity and neurotoxicity. ${ }^{4}$ Because cancer 
patients require long-term treatment, development of oral formulations for paclitaxel is urgently needed to improve patient compliance and preserve quality of life.

Presently, a great deal of research effort has been devoted to increasing the water solubility of paclitaxel and improving its oral bioavailability. Modification of the chemical structure and development of new drug-delivery systems, such as self-emulsifying formulations, liposomes, nanoparticles, and polymeric micelles, has shown promising potential to replace the Cremophor EL-based vehicle for delivery of paclitaxel. ${ }^{2,5-9}$

Lipid-based liquid crystalline nanoparticles (LCNPs) are attracting growing interest as nanocarrier systems due to their potential to improve the bioavailability of both hydrophilic and hydrophobic drugs. ${ }^{10,11}$ LCNPs, which are self-assembled from polar amphiphilic lipids in the presence of excess water, are generally prepared by dispersing the nonlamellar liquid crystalline matrix formed into water phase using high-energy fragmentation, such as ultrasonication, microfluidization, or homogenization. ${ }^{12}$ Depending on the nature of the different lipids and the various additives and solution conditions, the structures formed may include lamellar $\left(\mathrm{L}_{\alpha}\right)$, bicontinuous cubic $\left(\mathrm{Q}_{2}\right)$, and reversed hexagonal $\left(\mathrm{H}_{2}\right)$ phases, and in some particular cases, a discrete micellar cubic phase $\left(\mathrm{I}_{2}\right){ }^{13}$ The discrete/bicontinuous aqueous channel and lipid domains inside LCNPs make it possible to encapsulate drugs with different polarity. ${ }^{14}$ In addition, despite their huge surface area, LCNPs have unique two-dimensional and three-dimensional thermodynamically stable properties. ${ }^{15}$ Furthermore, lipid-based LCNPs are biocompatible, digestible, and bioadhesive. Therefore, it is believed that LCNPs might serve as novel drug-delivery systems combining the advantages of liposomes and nanoparticles by providing protection and enabling sustained release of agents solubilized in LCNPs.

Recently, a new lipid liquid crystalline matrix prepared from soy phosphatidylcholine and glycerol dioleate was reported, ${ }^{16}$ in which self-assembled reversed micellar cubic $\left(\mathrm{I}_{2}\right)$ and hexagonal $\left(\mathrm{H}_{2}\right)$ phases were observed when soy phosphatidylcholine and glycerol dioleate were mixed in equal proportions, with addition of $10 \%-30 \%$ water. In previous studies, soy phosphatidylcholine/glycerol dioleate/polysorbate 80-based LCNPs showed an extended terminal half-life for intravenous delivery of both hydrophobic and hydrophilic drugs. ${ }^{17,18}$ Nevertheless, application of this LCNP system for oral drug administration has barely been explored. In addition, the cellular interaction between LCNPs and enterocytes remains to be defined.
In this research, a soy phosphatidylcholine/glycerol dioleate-based LCNP system was developed as an oral delivery platform for poorly water-soluble drugs. Paclitaxel, a class IV drug in the biopharmaceutics classification system, was chosen as the model agent. The phase behavior of bulk liquid crystalline matrices was characterized via crossed polarized light microscopy and small-angle X-ray scattering. The morphology of the nanoparticles was examined under a transmission electron microscope and a cryofield field emission scanning electron microscope (cryo-FESEM). Cytotoxicity, membrane fluidity, and cellular uptake of LCNPs were carried out using Caco-2 cells as the endothelial cell model. Nile red and N-(7-nitrobenz2-oxa-1, 3-diazol-4-yl)-1, 2-dihexadecanoyl-sn-glycero-3phosphoethanolamine (NBD-PE) were used as fluorescent probes to show the intracellular behavior of LCNPs under confocal laser scanning microscopy. An in vivo pharmacokinetic study was conducted to evaluate the ability of this LCNP system to deliver hydrophobic agents orally.

\section{Materials and methods Materials and animals}

Soy phosphatidylcholine, Lipoid S100 (containing phosphatidylcholine 95.2\%) was purchased from Toshisun (Lipoid, Ludwigshafen, Germany). Glycerol dioleate was obtained from $\mathrm{J}$ and $\mathrm{K}$ (Beijing, China). Paclitaxel was purchased from Xi' an Sanjiang Biological Engineering Co, Ltd (Xi'an, China) and Taxol from Bristol-Myers Squibb (Princeton, NJ). Nile red and 1, 6-diphenyl-1,3,5-hexatriene (DPH) were obtained from Sigma-Aldrich (Shanghai, China). NBD-PE was obtained from Invitrogen (Burlington, ON), and polysorbate-80 from Dazhong Co, Ltd (Shanghai, China). All other reagents were of analytical or chromatographic pure grade and purchased from Sinopharm Chemical Reagent Co, Ltd (Shanghai, China).

Cell counting kit-8 (CCK-8) solution was provided by Dojindo (Kumamoto, Japan). Dulbecco's modified Eagle's medium (DMEM) was obtained from Hyclone (Logan, US). Fetal bovine serum, $0.25 \%$ trypsin-ethylenediamine tetraacetic acid, penicillin-streptomycin, and nonessential amino acids were purchased from Gibco (Beijing, China).

Male Sprague Dawley rats (weighing $200 \pm 20 \mathrm{~g}$ ) were obtained from the Experimental Animal Center of Fudan University and housed at $22^{\circ} \mathrm{C} \pm 2{ }^{\circ} \mathrm{C}$ with access to food and water ad libitum. The protocol for animal experiments was approved by the Animal Experimentation Ethics Committee of Fudan University. 


\section{Preparation of LCNPs}

LCNPs were prepared using a modified solvent precursor method. ${ }^{19}$ Soy phosphatidylcholine, glycerol dioleate, and polysorbate 80 , with or without paclitaxel, were mixed with the hydrotrope $(10 \%$ ethanol to total additives, w/w) and stirred for 3 hours to form a uniform and clear oil phase. HEPES ( $\mathrm{N}^{\prime}$-a-hydroxythylpiperazine- $\mathrm{N}^{\prime}$-ethanesulfanic acid) solution (containing $20 \mathrm{mM}$ HEPES, $\mathrm{pH} 7.4,20 \%$ to lipid, w/w) was gently added to the oil phase. The mixture was then incubated under stirring at room temperature for at least 24 hours (entrapment of air bubbles was carefully prevented by adjusting the stirring speed) to form a bulk liquid crystalline matrix. This liquid crystalline precursor was then injected into HEPES solution under magnetic stirring at $60^{\circ} \mathrm{C}$ to form a coarse dispersion, and subsequently homogenized with a Microfluidizer (Nano DeBEE, South Easton, MA) at a pressure of 10,000 psi for three cycles and 30,000 psi for two cycles. Nile red and/or NBD-PE were incorporated as fluorescent probes, and prepared using the same procedures as those used to prepare the paclitaxel-loaded LCNPs.

\section{Phase behavior of bulk liquid crystalline matrix}

The phase behavior of the bulk liquid crystalline matrix was characterized using crossed polarized light microscopy with a Zeiss Axiovert 40 MAT microscope (Carl Zeiss, Oberkochen, Germany) fitted with an AxioCam camera. Small-angle $\mathrm{X}$-ray scattering (SAXSess mc2, Anton-Paar, Austria) was utilized to confirm further the internal structure of the liquid crystalline phase.

\section{Characterization of LCNPs}

The mean diameters of the nanoparticles were determined by dynamic light scattering using a Zeta Potential/Particle Sizer 380 ZLS (PSS Nicomp, Santa Barbara, CA). Morphological examination of LCNPs was carried out using a transmission electron microscope (H-600, Hitachi, Japan) following negative staining with sodium phosphotungstate solution. To study further the surface morphology of the LCNPs, the samples were examined under cryo-FESEM (Hitachi, S-4800, Japan) with liquid nitrogen freezing and gold sputtering $\left(-100^{\circ} \mathrm{C}\right)$.

\section{Encapsulating efficiency, loading capacity, and in vitro drug release}

The encapsulating efficiency (EE\%) and loading capacity (LC\%) of paclitaxel in LCNPs were determined by gel filtration chromatography, as described elsewhere. ${ }^{20}$ The eluate containing LCNPs was dissolved in methanol to release paclitaxel. The content of paclitaxel was analyzed using a high-performance liquid chromatography system (Shimadzu, Tokyo, Japan). Methanol/water (75/25, v/v) was used as the mobile phase at a flow rate of $1.2 \mathrm{~mL}$ per minute. Paclitaxel was separated by a C18 column (Diamonsil, $5 \mu \mathrm{m}, 4.6 \times 200 \mathrm{~mm}$; Dikma, Beijing, China) and detected at $227 \mathrm{~nm}$. The $\mathrm{EE} \%$ and $\mathrm{LC} \%$ were calculated as indicated below $(n=3)$,

$$
\begin{gathered}
\mathrm{EE} \%=\frac{\mathrm{PTX} \text { in cubic nanoparticles }}{\text { Total amount of PTX in dispersion }} \times 100 \% \\
\mathrm{LC} \%=\frac{\text { PTX in cubic nanoparticles }}{\text { Nanoparticles weight }} \times 100 \%
\end{gathered}
$$

In vitro drug release from the LCNPs was performed using an equilibrium dialysis method. Paclitaxel-loaded LCNPs and Taxol (containing $0.03 \mathrm{mg}$ paclitaxel) were added into a sealed dialysis bag (molecular weight cutoff $9 \mathrm{kDa}$ ) with a plastic cork, immersed in $30 \mathrm{~mL}$ of release medium (HEPES solution with $0.1 \% \mathrm{v} / \mathrm{v}$ polysorbate 80 for providing sink conditions throughout the release test, $\mathrm{pH}$ 6.8) and incubated at $37^{\circ} \mathrm{C}$ with a shaking speed of $100 \mathrm{rpm}$. A $0.2 \mathrm{~mL}$ volume of release medium was sampled at $0,0.5,1,2,3$, $4,6,8,16,24,48,72$, and 96 hours, followed by immediate addition of an equal volume of fresh release medium. Samples were analyzed using the high-performance liquid chromatography method mentioned above.

\section{Caco-2 cell culture}

A human colon adenocarcinoma (Caco-2) cell line was obtained from the American Type Culture Collection (Rockville, MD) and grown in a $5 \% \mathrm{CO}_{2}$ humidified atmosphere at $37^{\circ} \mathrm{C}$ in DMEM medium supplemented with $10 \%$ fetal bovine serum, $1 \%$ nonessential amino acids, penicillin $100 \mathrm{U} / \mathrm{mL}$, and streptomycin $100 \mathrm{mg} / \mathrm{L}$.

\section{CCK-8 cell viability analysis}

In vitro proliferation of the Caco-2 cells was accessed using a CCK-8 assay to evaluate the cytotoxicity of LCNPs. Caco-2 cells were seeded into a 96-well plate at a density of 5000 cells/well and cultured for 24 hours. Following that, the cells were incubated with LCNPs for 24 hours at concentrations of $100 \mathrm{mg} / \mathrm{L}, 200 \mathrm{mg} / \mathrm{L}, 500 \mathrm{mg} / \mathrm{L}, 1 \mathrm{mg} / \mathrm{mL}, 2 \mathrm{mg} / \mathrm{mL}$, $5 \mathrm{mg} / \mathrm{mL}, 10 \mathrm{mg} / \mathrm{mL}, 100 \mathrm{mg} / \mathrm{mL}$, and $200 \mathrm{mg} / \mathrm{mL}$ (w/w). 
Immediately after treatment with LCNP, the medium was changed back to DMEM, and $0.01 \mathrm{~mL}$ of CCK-8 solution was added to each well. The cells were further incubated at $37^{\circ} \mathrm{C}$ for 2 hours, and color development was quantified photometrically at $450 \mathrm{~nm}$ using a multifunction microplate reader (Thermo Fisher Scientific, Pittsburg, PA). Caco-2 cell proliferation at the same concentration of Cremophor EL:ethanol (1:1, v/v) was also evaluated. Untreated cells were used as controls and a cell-free well with an equal volume of DMEM as a blank. Viability (\%) was calculated as indicated below $(n=3)$,

$$
\text { Viability } \%=\frac{\operatorname{Abs}(\text { sample })-\operatorname{Abs}(\text { blank })}{\operatorname{Abs}(\text { control })-\operatorname{Abs}(\text { blank })} \times 100 \%
$$

\section{Membrane fluidity}

Cell membrane fluidity induced by LCNPs was evaluated by determining the fluorescence polarization of 1,6-diphenyl-1, 3,5-hexatriene (DPH), as previously described..$^{21}$ Briefly, one milliliter of the cell suspension in DMEM $\left(3.5 \times 10^{5}\right.$ cells $\left./ \mathrm{mL}\right)$ was mixed with an equal volume of $0.2 \mathrm{mM}$ cholesterol, $30 \mathrm{mM}$ benzyl alcohol, and $20 \mathrm{mg} / \mathrm{L}, 200 \mathrm{mg} / \mathrm{L}, 2 \mathrm{mg} / \mathrm{mL}$, and $20 \mathrm{mg} / \mathrm{mL}$ of empty LCNPs, respectively, followed by addition of DPH at a final concentration of $0.001 \mathrm{mM}$, and incubation for 30 minutes at $25^{\circ} \mathrm{C}$. Fluorescence anisotropy values were measured using a FLS 920 fluorescence lifetime steady-state spectrometer (Edinburgh, UK) at an excitation wavelength of $362 \mathrm{~nm}$ and an emission wavelength of $462 \mathrm{~nm}$. The membrane anisotropy value was given as a percentage of the blank control value.

\section{Cellular association of Nile red-labeled LCNPs}

A quantitative analysis of the cellular association of Nile redlabeled LCNPs was performed using a high-content analysis system, as described elsewhere. ${ }^{22}$ Briefly, Caco- 2 cells were seeded into a 96-well plate at a density of 5000 cells/well and cultured for 24 hours. After that, the cells were incubated with Nile red-labeled LCNPs in DMEM at concentrations of $4,8,16,32,64$, and $128 \mathrm{mg} / \mathrm{L}$ for 2 hours and $64 \mathrm{mg} / \mathrm{L}$ for $0.5,1,2,4$, and 6 hours. Immediately after treatment with LCNPs, the cells were washed three times with phosphate-buffered solution and fixed with $3.7 \%$ formaldehyde solution for 10 minutes. Following staining with $10 \mathrm{mg} / \mathrm{mL}$ Hoechst (bisbenzimide) 33258 at room temperature and away from light for 7 minutes, the cells were rinsed three times with phosphate-buffered solution and detected under a kinetic scan high-content analysis system reader (version 3.1; Cellomics Inc, Pittsburgh, PA) at a $20 \times$ objective. The cells were then treated with Trypan blue to quench the extracellular fluorescence and examined under the high-content analysis system once again. Cells treated with DMEM were used as controls. The assay protocol was configured to analyze 1000 cells per well, and all the experiments were performed in triplicate.

\section{Endocytotic pathway of LCNPs}

To study the endocytic pathway involved in LCNP internalization, cellular uptake experiments were performed in the presence of different inhibitors. Caco-2 cells were seeded in a 96-well plate at a density of 5000 cells/well and cultured for 24 hours. Cells were preincubated with $20 \mathrm{mM}$ sodium azide and $100 \mathrm{mM}$ 2-deoxyglucose $\left(\mathrm{NaN}_{3} / \mathrm{DOG}\right), 5 \mathrm{mM}$ methyl- $\beta$-cyclodextrin, filipin $10 \mathrm{mg} / \mathrm{L}$, cholesterol $40 \mathrm{mg} / \mathrm{L}$, chlorpromazine $16 \mathrm{mg} / \mathrm{L}$, and cytochalasin D $10 \mathrm{mg} / \mathrm{L}$ for 2 hours, respectively. After that, the cells were incubated with Nile red-labeled LCNPs (64 mg/L) in DMEM for 2 hours. Quantitative analysis of the cellular association of nanoparticles following the inhibitor treatments was performed as mentioned above and compared with that of the noninhibited controls.

\section{Intracellular behavior of LCNPs}

To understand further the intracellular behavior of LCNPs, the intracellular distribution of the fluorescencelabeled LCNPs was visualized by confocal laser scanning microscopy. Nile red was used as the model lipophilic agent and NBD-PE as the lipid component of the LCNPs. Caco-2 cells were seeded into multiple glass-bottomed tissue culture plates (10 mm; Shengyou Biotechnology Co, Ltd, Zhejiang, China) at an initial density of $1 \times 10^{5}$ cells/well and cultured for 24 hours before incubation with LCNPs that had been dual-labeled with Nile red $(0.1 \%)$ and NBD-PE (1\%) for $5,15,30,90$, and 240 minutes. Immediately after treatment with LCNPs, the cells were fixed, stained, and rinsed using the same method as mentioned above. Finally, the cells were examined under a Zeiss LSM 710 microscope.

\section{In vivo pharmacokinetics}

In order to evaluate the potency of LCNPs as nanocarriers for oral delivery of hydrophobic agents, the in vivo pharmacokinetics of paclitaxel-loaded LCNPs were investigated in Sprague Dawley rats after oral administration. The rats were fasted with water ad libitum 8 hours beforehand. Fifteen rats were randomly divided into three treatment groups, ie, for intravenous administration of Taxol, oral administration of 
Taxol, and oral administration of paclitaxel-loaded LCNPs, at a paclitaxel dose of $5 \mathrm{mg} / \mathrm{kg}$. Blood was collected into heparinized tubes at $0.083,0.25,0.5,1,1.5,2,4,6,8,12$, and 24 hours after administration. Plasma was collected following centrifugation and stored at $-20^{\circ} \mathrm{C}$ until analysis.

Plasma paclitaxel concentrations were determined by reverse-phase high performance liquid chromatography coupled with tandem mass spectrometry (LC-MS/MS). To prepare the samples for analysis, $90 \mu \mathrm{L}$ of methanol containing $60 \mathrm{ng} / \mathrm{mL}$ of docetaxel (internal standard) was added to $0.03 \mathrm{~mL}$ of plasma to precipitate the proteins. The mixture was vortexed and then centrifuged at 12,000 rpm for 10 minutes. The supernatant was mixed with an equal volume of deionized water, and $5 \mu \mathrm{L}$ of the sample was subjected to analysis in the LC-MS/MS system.

An API 4000 triple quadrupole LC-MS/MS system (Applied Biosystems, Toronto, ON) was used, and was equipped with an electrospray ionization source, a G1312A quaternary pump, a G1379A vacuum degasser, a G1316A thermostatted column oven (Agilent, Waldbronn, Germany), and an HTS PAL autosampler (CTC Analytics, Zwingen, Switzerland). A Venusil XBP phenyl column $(100 \mathrm{~mm} \times 2.1 \mathrm{~mm}$, $0.005 \mathrm{~mm}$; Agela, Shanghai, China) with a mobile phase of $0.1 \%$ formic acid:methanol (3:7) used for chromatographic separations. The flow rate and column temperature were set at $0.3 \mathrm{~mL}$ per minute and $40^{\circ} \mathrm{C}$, respectively. Quantitation was achieved with MS-MS detection in positive ion mode for all the analyses and internal standard. The ion spray voltage was set at $5000 \mathrm{~V}$. The source temperature was maintained at $500^{\circ} \mathrm{C}$. The ion source gas 1 (nitrogen), gas 2 (nitrogen), and curtain gas (nitrogen) pressures were set at 40, 55, and 20 psi, respectively. Nitrogen was used as the collision gas at a pressure of $4 \mathrm{~L} /$ minute for collision-activated dissociation. The parameters of the compound, including declustering potential, collision energy, entrance potential, and collision cell exit potential, were $160,30,10$, and $15 \mathrm{~V}$ for paclitaxel, and 140, 32, 10, and $15 \mathrm{~V}$ for docetaxel, respectively. Detection of the ions was performed in the multiple-reaction monitoring mode, by monitoring the transition pairs of the $\mathrm{m} / \mathrm{z} 876.6$ precursor ion to the $\mathrm{m} / \mathrm{z} 308.0$ for paclitaxel $(\mathrm{M}+\mathrm{Na})^{+}$, and $\mathrm{m} / \mathrm{z} 830.3$ precursor ion to the $\mathrm{m} / \mathrm{z} 549.1$ for docetaxel $(\mathrm{M}+\mathrm{Na})^{+}$, respectively. Quadrupoles Q1 and Q3 were set on unit resolution. Data acquisition was performed using the Analyst 1.4.1 software package (Applied Biosystems). All the concentration data are plotted as plasma drug concentration-time curves.

The pharmacokinetic analysis was performed using a model-independent method. The terminal elimination rate constant (k) was determined by least-square regression analysis of the terminal log-linear portions of the plasma concentration-time profile $(\mathrm{k}=-2.303 \times$ slope $)$. The elimination half-life $\left(\mathrm{T}_{1 / 2}\right)$ was calculated as $0.693 / \mathrm{k}$. The area under the curve to the last measurable concentration $\left(\mathrm{AUC}_{0-t}\right)$ was calculated using the linear trapezoidal rule. The area under the curve extrapolated to infinity $\left(\mathrm{AUC}_{0-\infty}\right)$ was calculated as $\mathrm{AUC}_{0-\mathrm{t}}+\mathrm{C}_{\mathrm{t}} / \mathrm{k}$, where $\mathrm{C}_{\mathrm{t}}$ is the last measurable concentration. Absolute bioavailability was calculated from the dosecorrected areas under the curves for oral versus intravenous administration.

\section{Statistical analysis}

Comparison among multiple groups was performed by one-way analysis of variance followed by the Bonferroni test. Comparison between two groups was performed using the Student's $t$-test. Statistical significance was defined as $P<0.05$.

\section{Results \\ Phase behavior of the bulk liquid crystalline matrix}

The phase behavior of the bulk liquid crystalline matrix was characterized using crossed polarized light microscopy and small-angle X-ray scattering. A birefringent fan-like texture was observed in the liquid crystalline matrix when in a dark environment. No significant change was found in the birefringent texture when $0.5 \%$ paclitaxel was incorporated into the bulk liquid crystalline phase (Figure 1A). As illustrated in Figure 1B, both the blank liquid crystalline matrix and the paclitaxel-loaded matrix showed three diffraction peaks in the small-angle X-ray scattering curves, with almost the same spacing ratio.

\section{Particle size and morphology of LCNPs}

A homogeneous solution with blue opalescence was obtained after homogenizing. The particle size of the blank LCNPs was $76.33 \pm 1.19 \mathrm{~nm}$ (polydispersity index $0.365 \pm 0.014$, Figure 2B). A slight increase in diameter was observed in the paclitaxel-loaded LCNPs $(84.70 \pm 5.26 \mathrm{~nm}$, polydispersity index $0.370 \pm 0.016$ ).

The morphology of the LCNPs was examined under a transmission electron microscope. As shown in Figure 2A, the nanoparticles formed had a spherical "flower-like" structure with an internal water channel. Albeit slightly smaller than that shown by dynamic light scattering, most LCNP diameters were in the range of 50-80 $\mathrm{nm}$. 
A
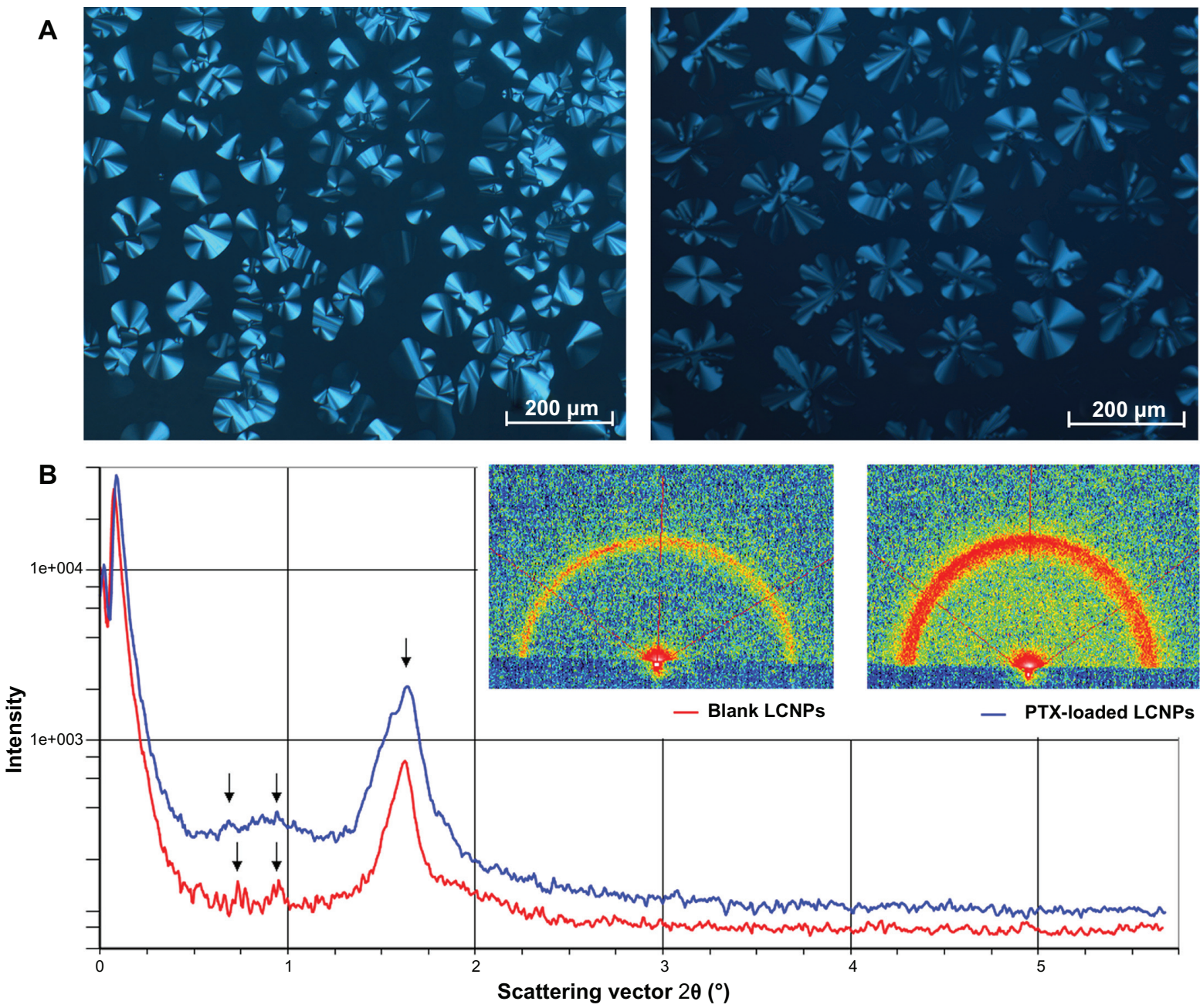

Figure I (A) Photomicrographs of bulk liquid crystalline matrices under crossed polarized light microscopy: left, blank liquid crystalline matrix; right, paclitaxel-loaded liquid crystalline matrix. (B) Small-angle X-ray diffraction pattern of liquid crystalline matrices: red line, blank liquid crystalline matrix; blue line, paclitaxel-loaded liquid crystalline matrix.

Abbreviations: LCNPs, liquid crystalline nanoparticles; PTX, paclitaxel.
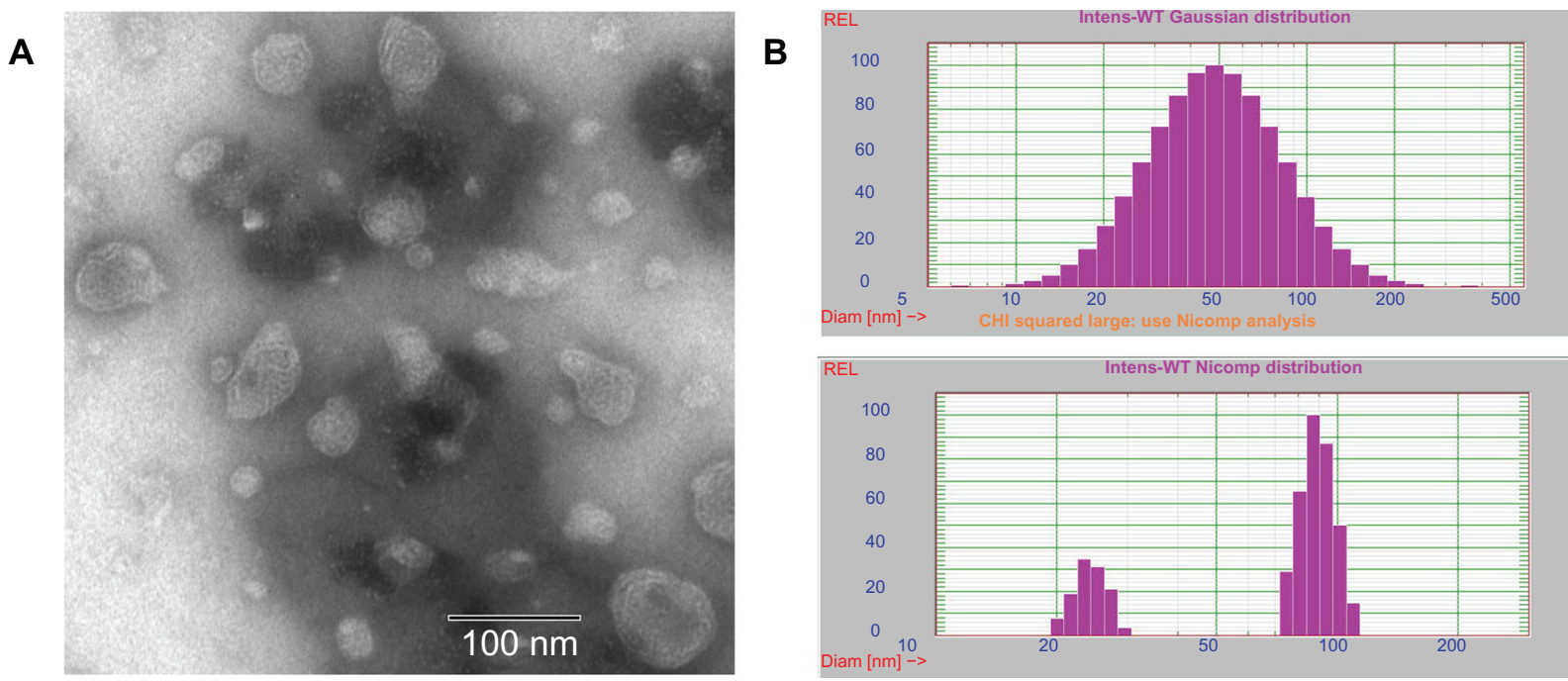

Figure 2 (A) Transmission electron microscopic images of liquid crystalline nanoparticles and (B) particle size of liquid crystalline nanoparticles when fit to Gaussian (up) and Nicomp (down) distributions, respectively. 
To study further the surface morphology of the LCNPs, the sample was examined under cryo-FESEM. The reversed micellar cubic particles exhibited a "ball-like" morphology, while the reversed hexagonal particles displayed clear hexagonal structures (Figure 3). LCNPs were found to be comprised of an internal nanostructured phase with enclosed water channels, with a relatively smooth but rough nodulelike appearance, as reported previously (data not shown). ${ }^{23}$

\section{Encapsulating efficiency, loading capacity, and in vitro drug release}

The EE\% and LC\% of paclitaxel-loaded LCNPs were $75 \%$ and $0.45 \%$, respectively. In vitro paclitaxel release from the LCNPs was determined using an equilibrium dialysis method. As shown in Figure 4, complete paclitaxel release from Taxol was obtained after 16 hours. LCNPs loaded with paclitaxel were shown to release their drug cargo in a sustained biphasic manner, with relatively fast drug release in the first 24 hours (50\% release) and slower release in the following 72 hours ( $70 \%$ total release).

\section{CCK-8 cell viability analysis}

Cell viability following LCNP treatment was measured using the CCK-8 assay to evaluate the safety of LCNPs as a novel nanovehicle for delivery of paclitaxel. As shown in Figure 5, Caco-2 cells were much less sensitive to LCNPinduced cytotoxicity. Compared with Cremophor EL:ethanol (1:1), a significant increase in cell viability was observed at a vehicle concentration of $1 \%-10 \%$. The Taxol vehicle decreased Caco-2 viability, with an $\mathrm{IC}_{50}$ of $0.8433 \mathrm{mg} / \mathrm{mL}$ after 24 hours of treatment, while LCNPs had an $\mathrm{IC}_{50}$ value of $11.05 \mathrm{mg} / \mathrm{mL}$.

\section{Membrane fluidity}

Given that LCNPs prepared from glyceryl monooleate have been reported to have lipid-mixing and membrane-fusion properties,${ }^{24}$ soy phosphatidylcholine/glycerol dioleatebased LCNPs might act similarly and may result in changes in microviscosity of the cell membrane following oral administration. The change in membrane fluidity induced by LCNPs was investigated by determining the fluorescence polarization of DPH within the Caco-2 cell membrane. As noted in Table 1, LCNPs at concentrations of $10 \mathrm{mg} / \mathrm{L}$ and $100 \mathrm{mg} / \mathrm{L}$ had almost no effect on membrane fluidity, with anisotropy values of $99.5 \%$ and $97.9 \%$, respectively. However, membrane fluidity was significantly increased after treatment with LCNPs at concentrations of $1 \mathrm{mg} / \mathrm{mL}$ and $10 \mathrm{mg} / \mathrm{mL}$, achieving decreased anisotropy values of $55.5 \%$ and $41.1 \%$, respectively.

\section{Cellular association of Nile red-labeled LCNPs}

High-content system analysis demonstrated that the cellular association of Nile red-labeled LCNPs in Caco-2 cells increased in both a concentration-dependent and timedependent manner (Figure 6). The same difference in fluorescent intensity before and after quenching was obtained 2, 4, and 6 hours after Nile red-labeled LCNP treatment,
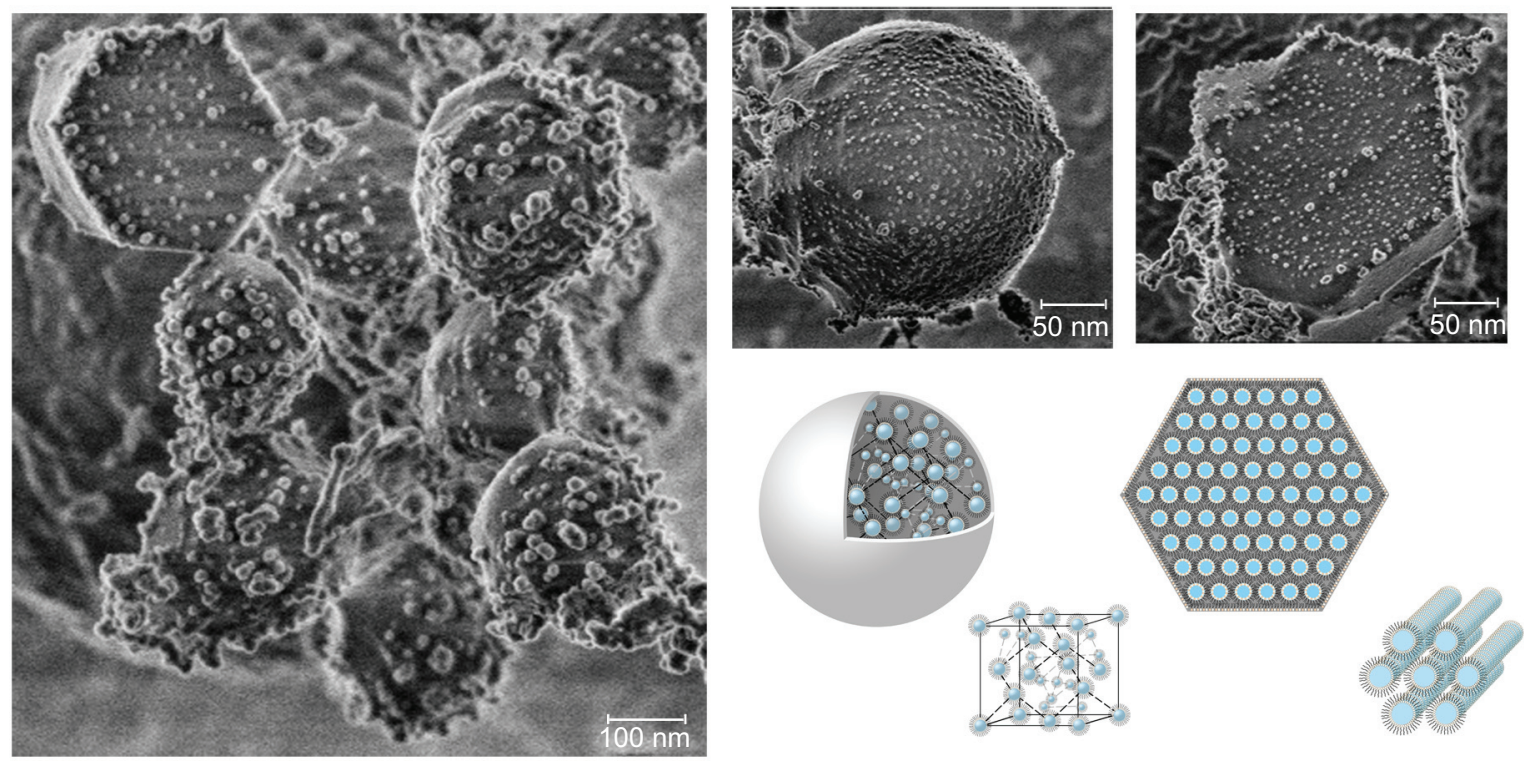

Figure 3 Cryo-field emission scanning electron microscopic images of liquid crystalline nanoparticles and schematic illustration of reversed micellar nanoparticles and reversed hexagonal nanoparticles. 


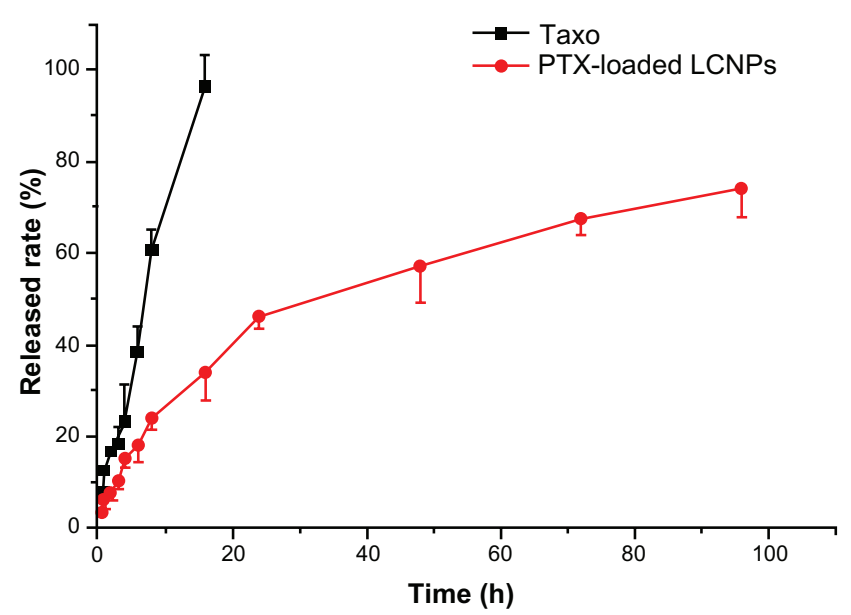

Figure 4 In vitro paclitaxel release from taxol and liquid crystalline nanoparticles in $\mathrm{pH} 7.4$ HEPES buffer at $37^{\circ} \mathrm{C}(\mathrm{n}=3)$.

Note: The initial paclitaxel concentration was $30 \mathrm{mg} / \mathrm{L}$.

Abbreviations: LCNPs, liquid crystalline nanoparticles; PTX, paclitaxel.

indicating that LCNPs readily attach to Caco-2 cell surfaces and reach a plateau rapidly (Figure 6B).

\section{Endocytosis pathway for LCNPs}

Endocytosis inhibition experiments showed that the cellular uptake of LCNPs was significantly increased by cholesterol but inhibited by chlorpromazine and filipin. $\mathrm{NaN}_{3} / \mathrm{DOG}$ and methyl- $\beta$-cyclodextrin were also associated with a reduction in cellular uptake of LCNPs, although the reduction was not statistically significant. No inhibition in uptake of LCNPs was found in cells pretreated with cytochalasin D (Figure 7). The inhibition efficiencies obtained before and after quenching were similar for most of the inhibitors, except

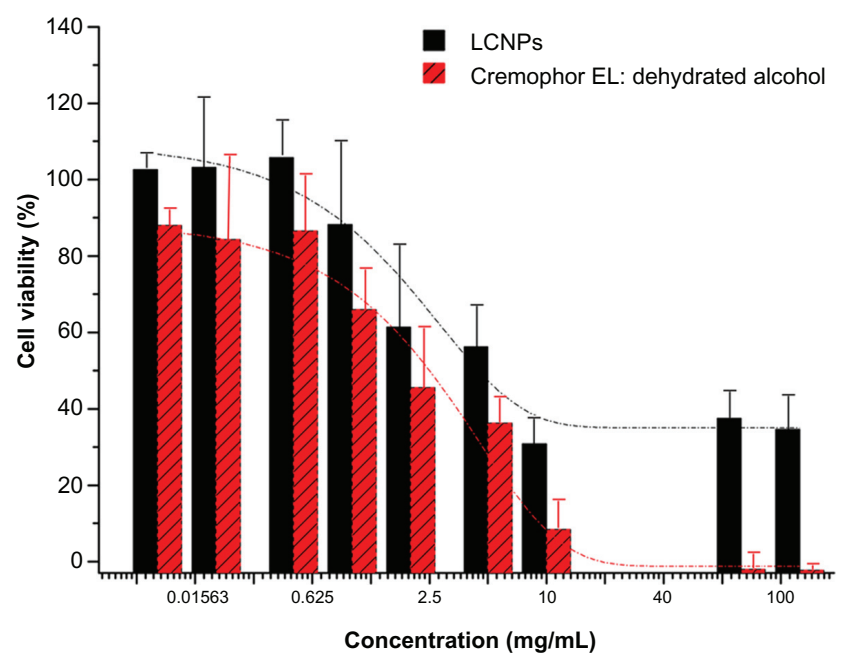

Figure 5 Viability of Caco-2 cells following 24 hours of treatment with liquid crystalline nanoparticles and Cremophor EL:ethanol (I:I).

Note: The dotted lines presented the fitted dose-response curves $(n=3)$.

Abbreviation: LCNPs, liquid crystalline nanoparticles.
Table I Anisotropy values for the DPH-labeled Caco-2 cell membrane after incubation with different concentrations of liquid crystalline nanoparticles at $25^{\circ} \mathrm{C}$ for 30 minutes

\begin{tabular}{lll}
\hline $\begin{array}{l}\text { Fluidity } \\
\text { modulators }\end{array}$ & $\begin{array}{l}\text { Anisotropy } \\
\text { value }\end{array}$ & $\begin{array}{l}\text { Ratio of } \\
\text { control }\end{array}$ \\
\hline Blank control & 0.3608 & $100.0 \%$ \\
Cholesterol $(0.2 \mathrm{mM})$ & 0.4075 & $113.0 \%$ \\
Benzyl alcohol $(30 \mathrm{mM})$ & 0.3034 & $84.1 \%$ \\
LCNPs $(10 \mu \mathrm{g} / \mathrm{mL})$ & 0.3590 & $99.5 \%$ \\
LCNPs $(100 \mu \mathrm{g} / \mathrm{mL})$ & 0.3532 & $97.9 \%$ \\
LCNPs $(I \mathrm{mg} / \mathrm{mL})$ & 0.2004 & $55.5 \%$ \\
LCNPs $(10 \mathrm{mg} / \mathrm{mL})$ & 0.1478 & $41.0 \%$ \\
\hline
\end{tabular}

Abbreviations: LCNPs, liquid crystalline nanoparticles; DPH, I, 6-diphenyl-1,3,5hexatriene.

for chlorpromazine, which showed higher inhibition after quenching of the extracellular fluorescence.

\section{Intracellular behavior of LCNPs}

To understand further the intracellular behavior of LCNPs, Caco-2 cells were treated with dual-labeled LCNPs (Nile red, red fluorescence; NBD-PE, green fluorescence) and examined under confocal laser scanning microscopy. As seen in Figure 8, strong fluorescent signals were observed in the cells 5 minutes after treatment with LCNPs, indicating that internalization of LCNPs occurred rapidly. In addition, the agents internalized showed a yellow (colocalization of red and green) signal throughout the cytoplasm, together with some separated red and green signals. With an increase in incubation time, green NPD-PE was found to segregate from the red LCNPs and insert into the cell membrane (Figure 9). Separation of the colocalized Nile red and NBD-PE was easily distinguished 30 minutes after LCNP treatment (Figure 9A). After 240 minutes of incubation, almost all the NBD-PE had separated from the LCNPs, leaving the Nile red-labeled LCNPs in the cytoplasm (Figure 9C). A three-dimensional image clearly shows that a considerable amount of NBD-PE escaped from the LCNPs, inserted into the membrane at 90 minutes, and exhibited a green "hat" covering the entire cell (shown by arrows, Figure 10).

\section{In vivo pharmacokinetics}

The plasma concentration profiles of paclitaxel after intravenous administration of Taxol at $5 \mathrm{mg} / \mathrm{kg}$ paclitaxel are shown in Figure $11 \mathrm{~A}$. The mean $\mathrm{AUC}_{(0-24 \mathrm{~h})}$ was $1333.30 \pm 182.45 \mu \mathrm{g} / \mathrm{L} \cdot \mathrm{h}$ and the $\mathrm{C}_{5 \min }$ was $1183.60 \pm 156.02 \mu \mathrm{g} / \mathrm{L}$. The $\mathrm{T}_{1 / 2}$ observed for paclitaxel was $5.10 \pm 0.79$ hours (Table 2).

Figure 11B shows the pharmacokinetic profiles of paclitaxel obtained after oral administration. The $\mathrm{AUC}_{(0-24 \mathrm{~h})}$ 
A
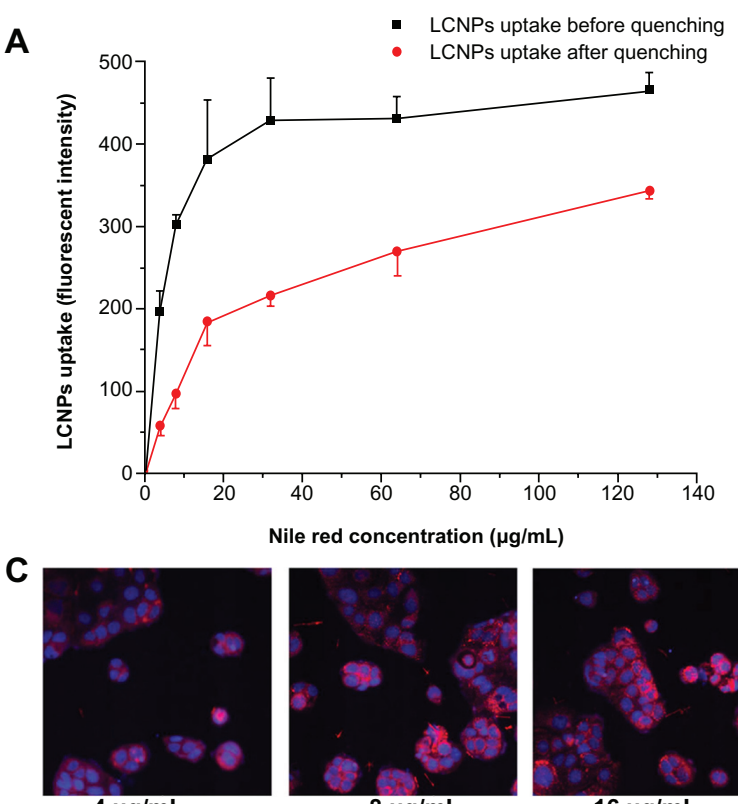

$4 \mu \mathrm{g} / \mathrm{mL}$

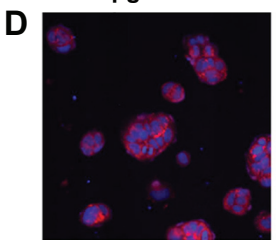

$0.5 \mathrm{~h}$

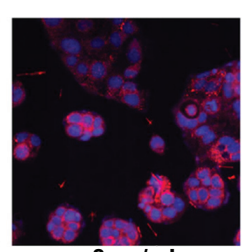

$8 \mu \mathrm{g} / \mathrm{mL}$

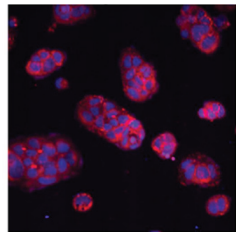

$1 \mathrm{~h}$

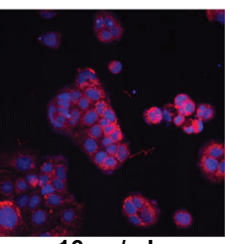

$16 \mu \mathrm{g} / \mathrm{mL}$

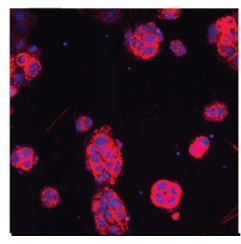

$2 \mathrm{~h}$
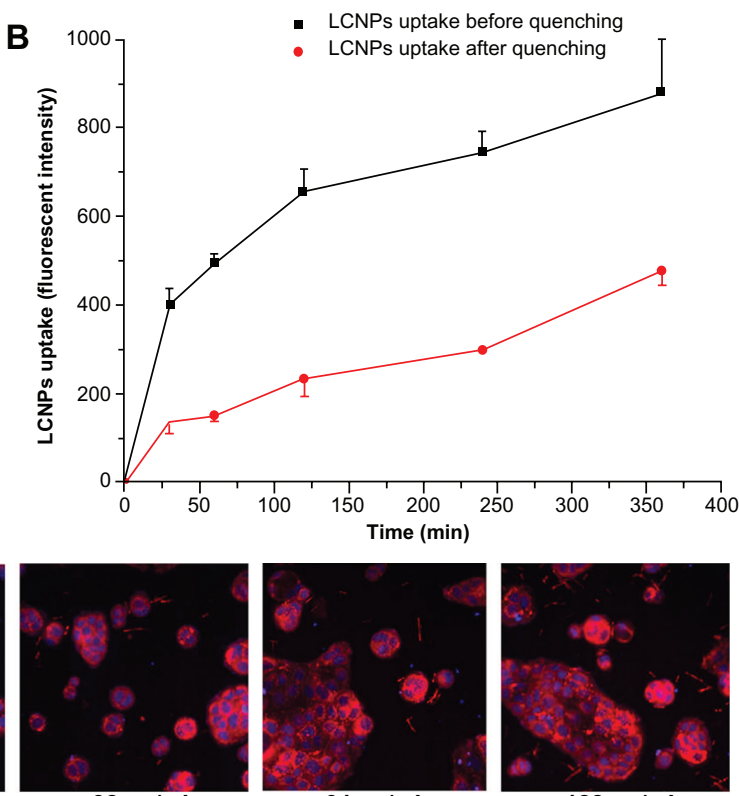

$32 \mu \mathrm{g} / \mathrm{mL}$

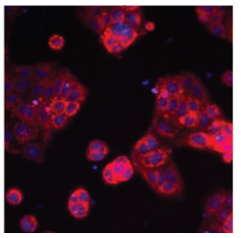

$4 \mathrm{~h}$

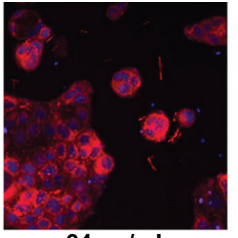

$64 \mu \mathrm{g} / \mathrm{mL}$

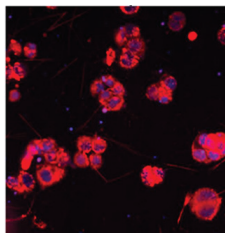

$6 \mathrm{~h}$

Figure 6 Cellular association of Nile red-labeled liquid crystalline nanoparticles in Caco-2 cells $(n=3)$. (A and $\mathbf{C})$ treated with Nile red-labeled liquid crystalline nanoparticles at concentrations of $4,8,16,32,64$, and $128 \mathrm{mg} / \mathrm{L}$ for 2 hours. (B and D) treated with Nile red-labeled liquid crystalline nanoparticles at a concentration of $64 \mathrm{mg} / \mathrm{L}$ for 0.5 , I, 2, 4, and 6 hours. (C and D) Fluorescent images after quenching. Red, Nile red-labeled liquid crystalline nanoparticles; blue, cell nuclei stained with Hoechst. Abbreviation: LCNPs, liquid crystalline nanoparticles.

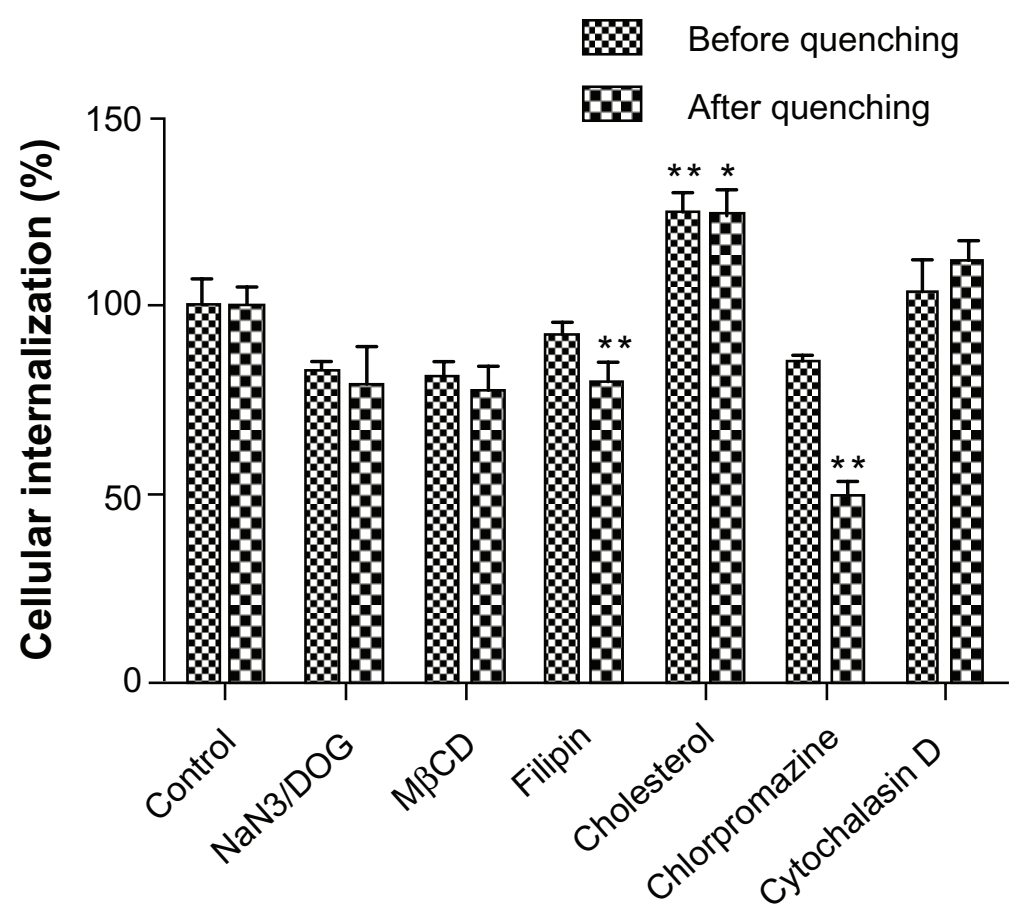

Figure 7 Cellular association of Nile red-labeled liquid crystalline nanoparticles in the presence of different endocytosis inhibitors. Notes: Data shown as the mean \pm standard deviation $(n=3)$. $* P<0.05$ and $* * P<0.0$ I, significantly different from controls. Abbreviation: $M \beta C D$, methyl- $\beta$-cyclodextrin. 


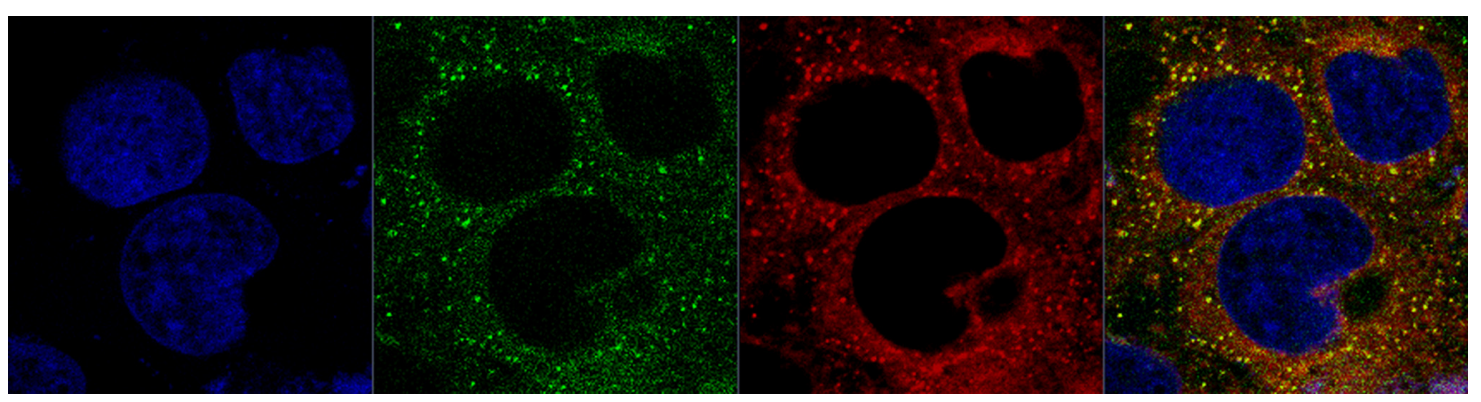

Figure 8 Confocal image of internalization of dual-labeled liquid crystalline nanoparticles by Caco-2 cells at 5 minutes.

Notes: Liquid crystalline nanoparticles was prepared using NBD-PE (green) as a lipid component within the nanoparticles and Nile red (red) as a fluorescent probe for the nanoparticles. Blue, cell nuclei stained with Hoechst; yellow, colocalization of Nile red and NBD-PE.

Abbreviation: NBD-PE, N-(7-nitrobenz-2-oxa-I, 3-diazol-4-yl)-I, 2-dihexadecanoyl-sn-glycero-3-phosphoethanolamine.

of paclitaxel-loaded LCNPs was 2.1 times that of Taxol. The $\mathrm{C}_{\max }$ of paclitaxel-loaded LCNPs and Taxol were $33.50 \pm 5.46 \mu \mathrm{g} / \mathrm{L}$ and $12.65 \pm 3.52 \mu \mathrm{g} / \mathrm{L}(P=0.000095)$, respectively, with a similar $\mathrm{T}_{\max }$. No significant difference was observed in the $\mathrm{T}_{1 / 2}$ for paclitaxel-loaded LCNPs and Taxol. The absolute bioavailability calculated for paclitaxel delivered in the LCNPs and Cremophor EL:ethanol formulations was $13.16 \%$ and $6.39 \%$, respectively (Table 2 ).

\section{Discussion}

In this paper, LCNPs were developed as nanovehicles for oral delivery of poorly water-soluble agents. The discrete

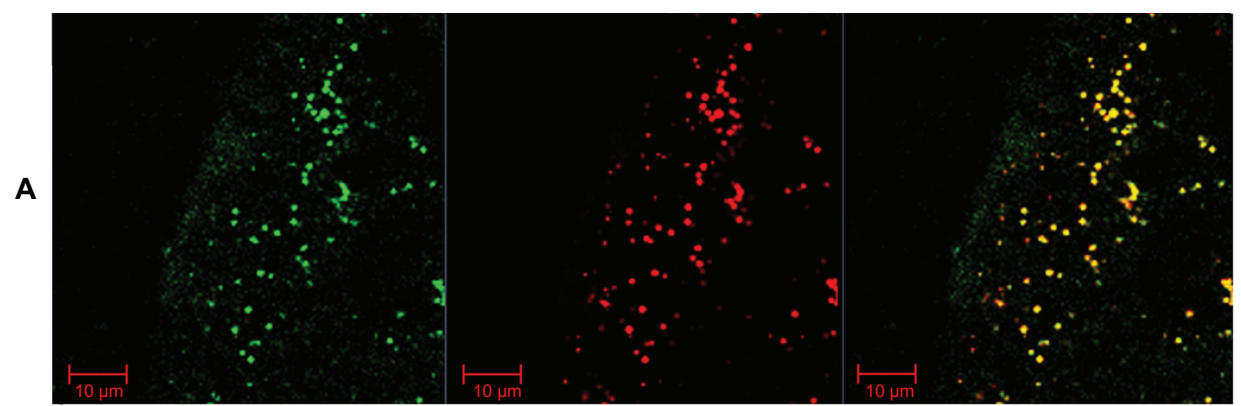

B
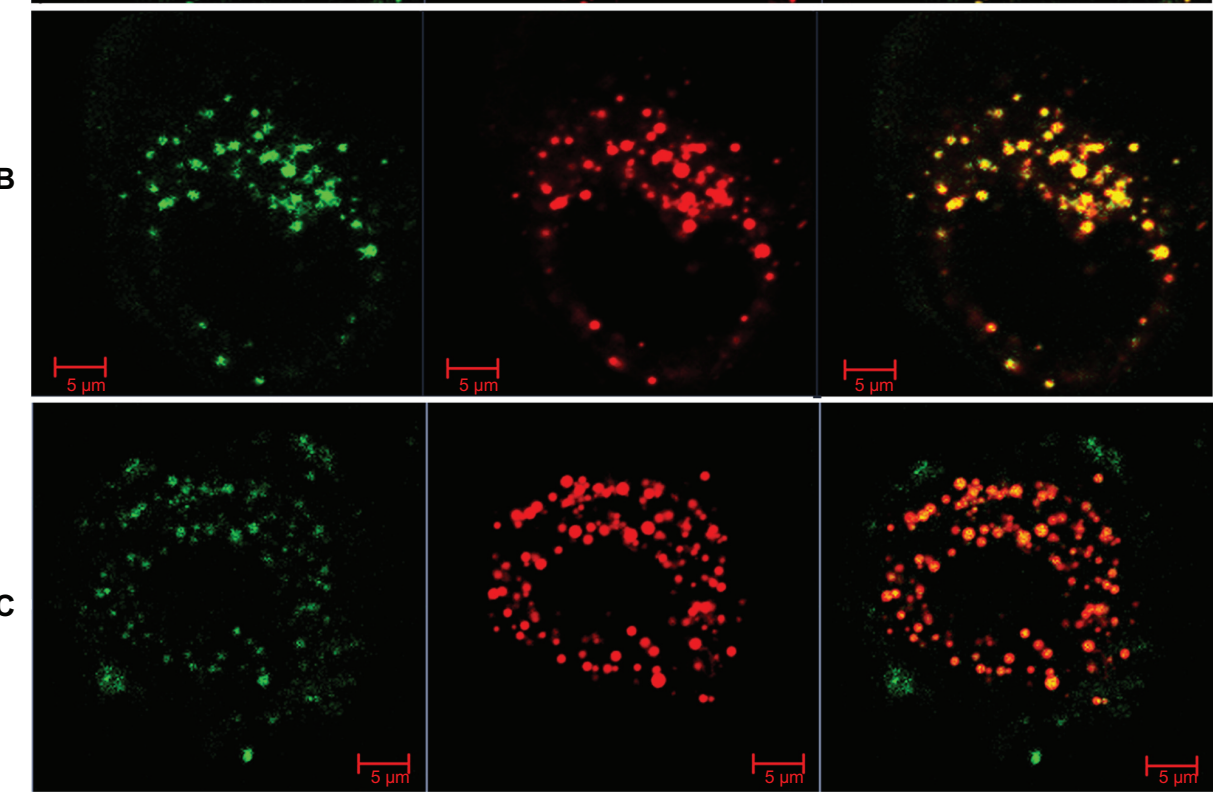

Figure 9 Confocal images of Nile red-labeled and NBD-labeled liquid crystalline nanoparticles in Caco-2 cells. (A) Most NBD colocalized with Nile red at 30 minutes, (B) NBD still colocalized with Nile red, and partly separated from Nile red at 90 minutes, and (C) most NBD separated with Nile red and inserted into the cell membrane at 240 minutes. Red, Nile red; green, NBD-PE.

Abbreviations: NBD, N-(7-nitrobenz-2-oxa-I, 3-diazol-4-yl)-I; NBD-PE, N-(7-nitrobenz-2-oxa-I, 3-diazol-4-yl)-I, 2-dihexadecanoyl-sn-glycero-3-phosphoethanolamine. 
A

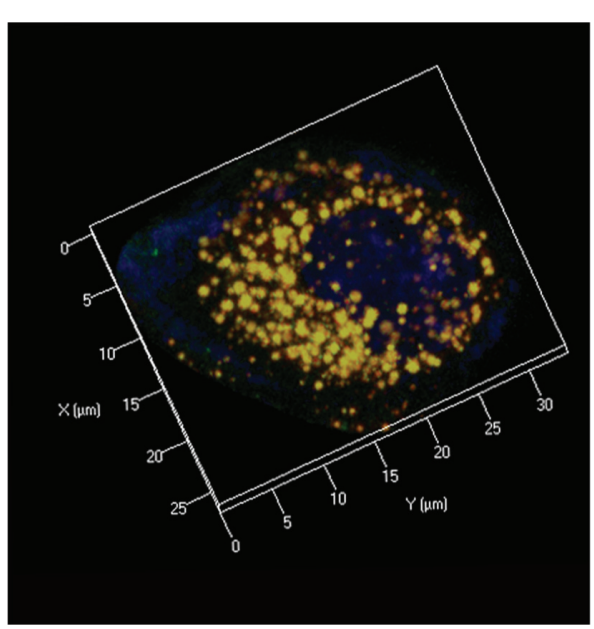

B

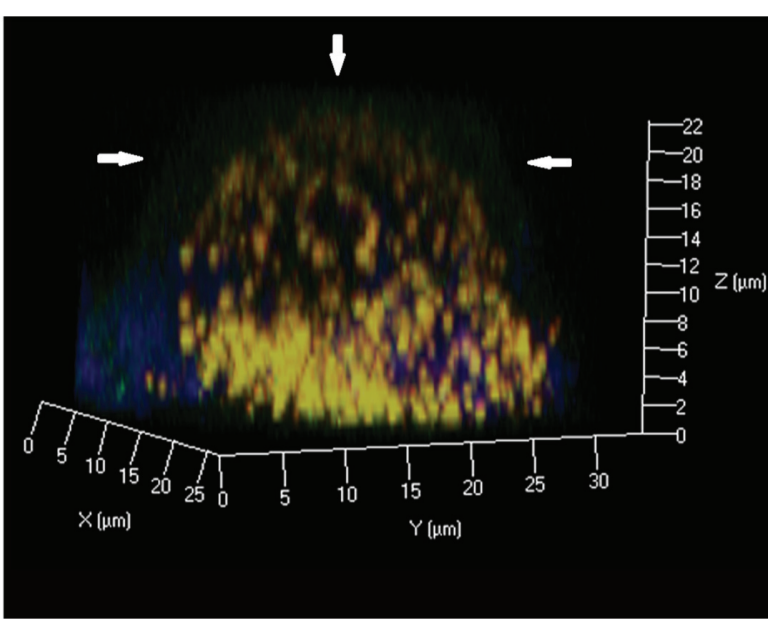

Figure 10 Confocal three dimensional images of Nile red-labeled and NBD-labeled liquid crystalline nanoparticles in Caco-2 cells at 90 minutes. (A) Top view and (B) side view. Red, Nile red; green, NBD-PE; blue, cell nuclei stained with Hoechst.

Note: Arrow, NBD-PE separated from liquid crystalline nanoparticles and inserted into the cell membrane.

Abbreviation: NBD-PE, N-(7-nitrobenz-2-oxa-I, 3-diazol-4-yl)-I, 2-dihexadecanoyl-sn-glycero-3-phosphoethanolamine.

lipidic hydrophobic and aqueous hydrophilic domains within LCNPs have been used for diffusion-controlled release of hydrophobic, hydrophilic, and amphiphilic molecules. ${ }^{14}$ However, the potential of LCNPs as oral drug nanovectors has not been fully explored, especially the internalization mechanism in intestinal epithelium cells. In this study, a soy phosphatidylcholine/glycerol dioleate-based LCNP system was prepared and characterized using crossed polarized light microscopy, small-angle $\mathrm{X}$-ray scattering, transmission electron microscopy, and cryo-FESEM. In vitro release and in vivo pharmacokinetics of the paclitaxel-loaded LCNPs were evaluated. In vitro Caco-2 cell experiments were carried out to evaluate the mechanism of uptake of LCNPs by cells.

The phase behavior of the liquid crystalline matrix was studied using crossed polarized light microscopy and smallangle X-ray scattering. Crossed polarized light microscopy has a long history of providing information about the phase behavior of a liquid crystalline matrix. Small-angle X-ray scattering was used as a tool complementary to crossed polarized light microscopy for phase identification to provide a better understanding of the spacing ratio of the liquid crystalline phases. In this study, crossed polarized light microscopy data revealed the coexistence of reversed cubic and hexagonal phases $\left(\mathrm{H}_{2}\right.$ and $\left.\mathrm{I}_{2}\right)$. Although it was hard to infer the space pattern of coexisting $\mathrm{H}_{2}$ and $\mathrm{I}_{2}$ phases from three diffraction peaks, our small-angle X-ray scattering data still at least partly reflect crystallization of the bulk phase. On the other hand, it has been reported that incorporation of additives in lipid cubic phase can interact with or modify the structure of the cubic phases. ${ }^{25}$ However, in our study, negligible change in birefringent texture was observed in the presence of paclitaxel ( $0.5 \%$ in the total additives, Figure $1 \mathrm{~A})$, indicating that no phase conversion occurred following incorporation of paclitaxel. Such speculation was justified by our small-angle X-ray scattering data, which showed the same spacing ratio in both the paclitaxel-loaded liquid crystalline matrix and the paclitaxel-free one (Figure 1B).

LCNPs were prepared using a solvent precursor method. ${ }^{19}$ As shown in Figure 2B, the LCNPs constructed showed a bimodal polydispersed population with two distribution peaks (around $100 \mathrm{~nm}$ and $25 \mathrm{~nm}$ ) and relative wide size distributions (polydispersity index $0.360-0.380$ ). The particle distribution pattern was confirmed by our transmission electron microscopy data (Figure 2A), in which quite a few small particles (around $20 \mathrm{~nm}$ ) were observed in the LCNP formulation. It has been pointed out that such extremely small particles might not originate from larger particles as a result of high shear forces during homogenization but form spontaneously without the need for a high energy input. ${ }^{26}$

LCNPs showed winding water channels under transmission electron microscopy (Figure 2A) and a "balllike"/"hexagonal" morphology under cryo-FESEM (Figure 3), which confirmed the nanostructure of LCNPs, as shown in Figure 3. Nonlamellar liquid crystalline matrices $\left(\mathrm{Q}_{2}\right.$ and $\left.\mathrm{H}_{2}\right)$ can be prepared from original lipid combinations without any energy input. In addition, dispersions of liquid crystalline matrices maintain their unique internal structure, with distinct two-dimensional and three-dimensional thermodynamic stability. ${ }^{15}$ Thus, they might provide a promising 

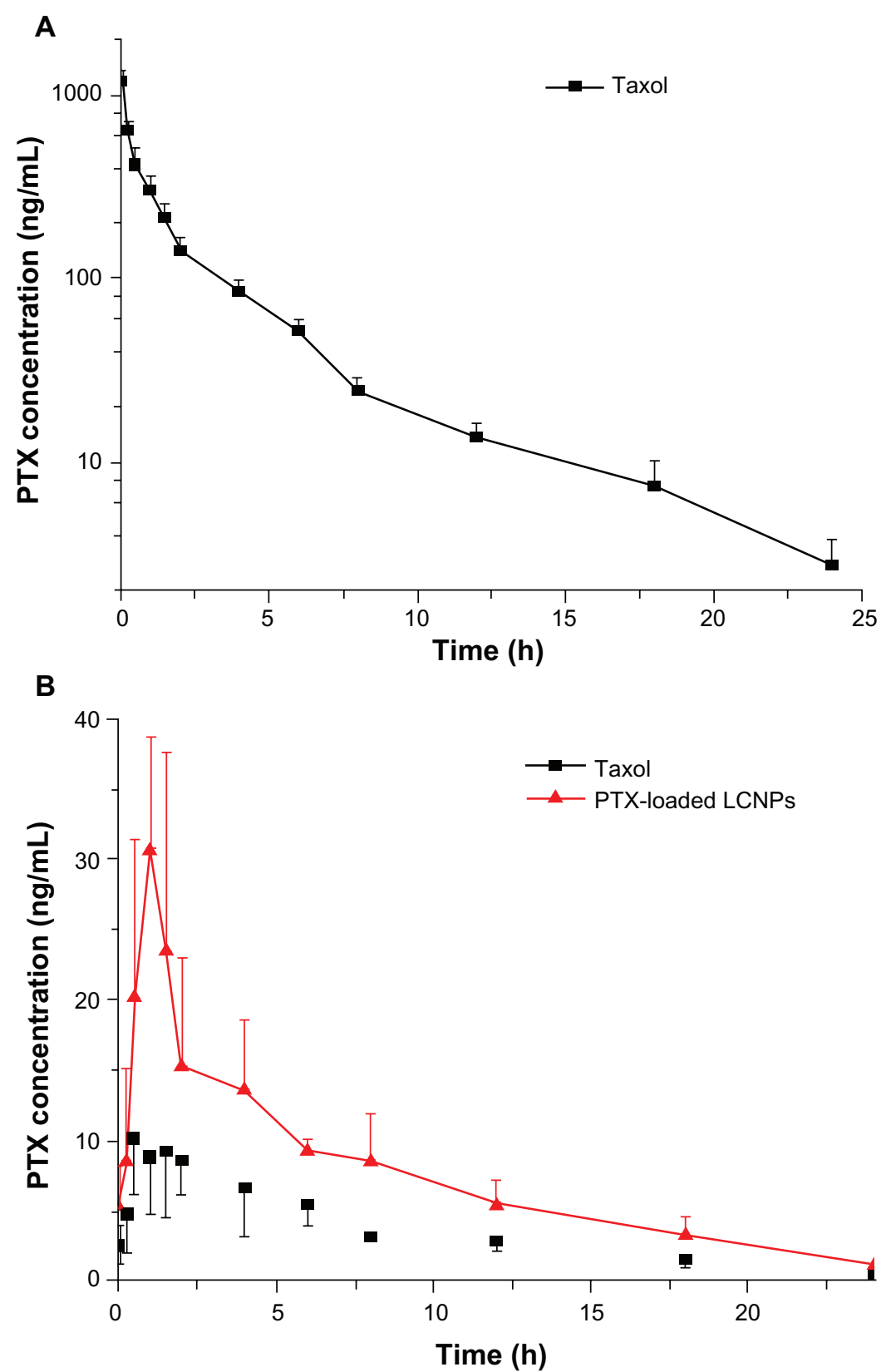

Figure II Plasma paclitaxel concentration-time profiles after (A) intravenous administration and (B) oral administration of Taxol ${ }^{\circledR}$ and paclitaxel-loaded liquid crystalline nanoparticles to Sprague-Dawley rats at a paclitaxel dose of $5 \mathrm{mg} / \mathrm{kg}(\mathrm{n}=5)$.

Abbreviations: LCNPs, liquid crystalline nanoparticles; PTX, paclitaxel.

sustained release drug nanocarrier system beyond traditional drug-delivery systems. On the other hand, cryo-FESEM seemed to yield somewhat larger diameters than dynamic light scattering and transmission electron microscopy, which we believe resulted from particle aggregation or water channel swelling at $-100^{\circ} \mathrm{C}$.

Although almost all liquid crystalline matrices have been reported to be sustained-release systems, ${ }^{27}$ a large amount of literature has reported burst release from LCNPs. ${ }^{28,29}$ The major limitation of the application of LCNPs is thought to correlate with the increased surface area when dispersed into excess water. ${ }^{30}$ In this study, LCNP nanocarriers showed sustained in vitro release of paclitaxel, with a relatively rapid release from LCNPs in the initial stage (over approximately 24 hours), and a slower release thereafter (during the following 72 hours, Figure 4). The initial rapid release is believed to derive from agents located at the outer layer of the particles. In contrast, the slower release is ascribed to those incorporated in the core of the nanocarrier and released in a sustained manner along with erosion or degradation of the matrix. 
Table 2 Pharmacokinetic parameters for paclitaxel after intravenous or oral administration of $\mathrm{Taxol}^{\circledR}$ and paclitaxelloaded liquid crystalline nanoparticles to Sprague-Dawley rats at a paclitaxel dose of $5 \mathrm{mg} / \mathrm{kg}$ (mean \pm standard deviation, $\mathrm{n}=5$ )

\begin{tabular}{|c|c|c|c|}
\hline & \multicolumn{2}{|l|}{ Intravenous } & \multirow{2}{*}{$\begin{array}{l}\text { Oral } \\
\text { PTX-loaded } \\
\text { LCNPs }\end{array}$} \\
\hline & Taxol $^{\circledR}$ & Taxol & \\
\hline$C_{5 \min }(\mu g / L)$ & $1183.60 \pm 156.02$ & & \\
\hline$C_{\max }(\mu g / L)$ & & $12.65 \pm 3.52$ & $33.50 \pm 5.46 * *$ \\
\hline $\mathrm{T}_{\max }(\mathrm{h})$ & & $0.90 \pm 0.42$ & $0.80 \pm 0.27$ \\
\hline $\mathrm{T}_{1 / 2}(\mathrm{~h})$ & $5.10 \pm 0.79$ & $5.22 \pm 0.76$ & $5.65 \pm 1.05$ \\
\hline $\operatorname{AUC}_{(0-24 h)}(\mu g / L \cdot h)$ & $1333.30 \pm 182.45$ & $82.01 \pm 19.68$ & $169.07 \pm 52.69 * *$ \\
\hline $\mathrm{AUC}_{(0-\infty)}(\mu g / L \cdot h)$ & $|354.3| \pm 193.06$ & $86.54 \pm 18.15$ & $178.24 \pm 52.84 * *$ \\
\hline $\begin{array}{l}\text { Absolute } \\
\text { bioavailability }\end{array}$ & & $6.39 \%$ & $13.16 \%$ \\
\hline
\end{tabular}

Notes: ${ }^{*} P<0.05$ and ${ }^{*} P<0.01$, significantly different from Taxol after ora administration. $* P<0.05$ and $* * P<0.01$, significantly different from that of the $\mathrm{Taxol}^{\circledR}$ group after oral administration.

Abbreviations: AUC, area under the concentration-time curve; $\mathrm{C}_{m_{2 x}}$, peak plasma concentration; $T_{1 / 2}$, elimination half-life; LCNPs, liquid crystalline nanoparticles; PTX, paclitaxel.

Cremophor EL, the excipient in Taxol, has been the subject of widespread safety concerns due to its side effect profile. ${ }^{3}$ These concerns emphasize the need for development of a safe and effective alternative formulation of paclitaxel. Soy phosphatidylcholine and glycerol dioleate are generally accepted to be safe for oral administration, and polysorbate 80 is approved by the US Food and Drug Administration as an excipient with good biocompatibility and biodegradability. However, it has been suggested that LCNPs could fuse with cellular lipid membranes, ${ }^{31,32}$ which raises the question of potential toxicity. Thus, to evaluate the cytotoxicity of LCNPs, cell viability following LCNP treatment was assessed in comparison with Cremophor EL:ethanol. As shown in Figure 5, compared with the Taxol vehicle, Caco-2 cells were much less sensitive to LCNP-induced cytotoxicity after 24 hours of treatment, showing a 12-fold higher $\mathrm{IC}_{50}$ than that of the Taxol vehicle. In addition, because LCNPs are formulated without Cremophor EL, their drug cargo is expected not to have the serious and potentially fatal hypersensitivity reactions that occur with Taxol. Accordingly, LCNPs can be considered to be promising alternative carriers for paclitaxel.

Although it has been pointed out that soy phosphatidylcholine/glycerol dioleate-based LCNPs show very limited lipid-mixing ability with model soy phosphatidylcholine membranes,$^{24}$ other researchers have claimed that mixtures of phosphatidylcholine and cholesterol could form stable inverted bicontinuous cubic phases under physiological conditions, thereby resulting in membrane "fusion". ${ }^{32}$ Therefore, it is necessary to determine the membrane fluidity of LCNPs in order to evaluate their impact on the cell membrane. In our steady-state fluorescence anisotropy study, positive controls (cholesterol) and negative controls (benzyl alcohol) increased and decreased the anisotropy values, respectively, suggesting that membrane fluidity was increased by cholesterol and decreased by benzyl alcohol. LCNPs had almost no effect on anisotropy values when their concentration was less than $100 \mathrm{mg} / \mathrm{L}$, but significantly decreased anisotropy values when their concentration increased up to $10 \mathrm{mg} / \mathrm{mL}$ (Table 1), suggesting that only LCNPs over a certain concentration could affect fluidity of the cell membrane.

In order to profile the cellular internalization of LCNPs, quantitative analysis of the cellular association of Nile red-labeled LCNPs was done using a high content analysis system. It has been reported that Nile red is a convenient fluorescent marker for labeling lipid dispersions ${ }^{33,34}$ and can be easily incorporated into lipid nanoparticles., ${ }^{8,35,36}$ Poorly soluble Nile red was expected to mix with the lipophilic domains of the particles and show minimal leakage in our preliminary experiment. Therefore, it was used as the fluorescent marker for LCNPs to evaluate their cellular interactions and uptake. On the other hand, an earlier study has argued that transferring of lipophilic markers from nanoparticles to the cell membrane could lead to overestimation of cellular uptake of nanoparticles. ${ }^{34}$ Therefore, Trypan blue was used to quench fluorescence on the cell membrane. From the data before and after quenching (Figure 6A and B), it was found that LCNPs readily attach to the plasma membrane, which could be as a result of the lipophilic properties of lipids and the bioadhesive properties of LCNPs. Internalization of LCNPs into the cytoplasm increased gradually, showing concentration-dependence and time-dependence.

Cellular endocytosis involves macropinocytosis, clathrinmediated endocytosis, or a caveolae/lipid raft-mediated mechanism. ${ }^{8}$ To characterize the endocytosis pathway involved in the cellular uptake of LCNPs, cellular uptake experiments were performed under ATP-depleted $\left(\mathrm{NaN}_{3} /\right.$ DOG), cholesterol-depleted (methyl- $\beta$-cyclodextrin), caveolae-inhibited (filipin), clathrin-inhibited (chlorpromazine), actin-disrupted (cytochalasin D), and cholesterolenriched (cholesterol) conditions, respectively.

The concentration-dependent, time-dependent, and energy-dependent cellular uptake of LCNPs (Figure 6) suggest that internalization of LCNPs was via active endocytosis. Incomplete inhibition of the LCNP interaction under biochemical ATP depletion $\left(\mathrm{NaN}_{3} / \mathrm{DOG}\right)$ might be attributed to mechanisms that mediate direct delivery, such 
as contact-mediated intermembrane lipid exchange/mixing and fusion of lipid particles.

Cellular uptake of LCNPs was also found to be inhibited by filipin and methyl- $\beta$-cyclodextrin (albeit not significantly so) but promoted by cholesterol (Figure 7). Lipid rafts are cholesterol-enriched and sphingolipid-enriched microdomains found in cell membranes, which play a significant role in many biological processes. ${ }^{35}$ It has been shown that both cholesterol and lipid raft involved in membrane trafficking are essential to the process of raft formation. As a specialized type of lipid raft, caveolae are flask-shaped invaginations in the plasma membrane, and are enriched with proteins as well as cholesterol and sphingolipids. Filipin, a sterolbinding pentaene macrolide antibiotic, which selectively inhibits caveolae invagination by formation of cholesterol precipitates, ${ }^{36}$ is generally used to block caveolae-mediated endocytosis. Methyl- $\beta$-cyclodextrin, a cyclic oligomer of glucopyranoside that inhibits cholesterol-dependent endocytic processes by reversibly extracting steroids from the plasma membrane, ${ }^{37}$ is often used to determine whether endocytosis is dependent on the integrity of the lipid raft. As shown in Figure 8, the significant increase in LCNP internalization by cholesterol and decreased uptake by filipin and methyl$\beta$-cyclodextrin indicates that caveolae/lipid raft-mediated endocytosis plays an important role in cellular uptake of LCNPs in Caco-2 cells.

Intracellular transport of LCNPs was inhibited significantly by chlorpromazine (Figure 7), an inhibitor which causes clathrin to accumulate in late endosomes and thereby inhibits coated pit-mediated endocytosis, ${ }^{38}$ indicating that clathrin-mediated uptake is also involved in the internalization of LCNPs. Furthermore, the fluorescence intensity in the presence of chlorpromazine showed a significant reduction after treatment with Trypan blue when compared with that before quenching, suggesting that clathrin-mediated endocytosis plays a major role in cellular internalization of LCNPs. These results suggest that at least two pathways exist in the cellular internalization of LCNPs, ie, clathrin-mediated and caveolae/lipid raft-mediated endocytosis.

As discussed above, LCNPs over a certain concentration may have an impact on the fluidity of the cell membrane. Due to susceptibility to membrane fusion, ${ }^{32}$ we speculated that soy phosphatidylcholine might segregate from LCNPs when attached to the cell membrane and induce lipid mixing or membrane fusion, and thereby increase absorption of paclitaxel. To explore further the mechanism of cellular delivery of LCNPs, LCNPs were formulated with
NBD-conjugated phosphatidylethanolamine and incorporated Nile red as the model agent. Both phosphatidylcholine and phosphatidylethanolamine are major constituent phospholipids in the cell membrane. In this study, NBD-PE was used as a fluorescent probe for soy phosphatidylcholine to show its behavior after cellular internalization.

Through observation of intracellular colocalization of Nile red and NBD-PE (Figure 8), our confocal laser scanning microscopy results showed that endocytosis of intact LCNPs might be a major mechanism for their intracellular drug transport. As shown in Figure 9, after 30-240 minutes of incubation, time-dependent lipid separation and membrane "fusion" of NBD-PE was observed, indicating that the lipid component could "stream" from LCNPs and distribute towards the plasma membrane, ie, exogenous LCNPs were trafficked into the cell via a particular endocytosis pathway, followed by intracellular divergence or degradation, enabling release of the lipid component and resulting in lipid particle fusion and/or lipid mixing. Figure 10 shows threedimensional images of Caco-2 cells after incubation with dual-labeled LCNPs for 90 minutes, which (especially the reconstructed image along the $\mathrm{z}$ axis) clearly demonstrates that the fluorescent signals of NBD-PE are mixed with the cell membrane. These findings confirm our results showing that LCNPs can alter the membrane fluidity, but is in contrast with previous studies concluding that lipophilic materials located in nanoparticles can be delivered easily and directly to the plasma membrane. ${ }^{39}$

The in vivo pharmacokinetics of paclitaxel formulated in Cremophor EL:ethanol or LCNPs after intravenous and oral administration are shown in Table 2 and Figure 11. Due to high expression of P-glycoprotein in intestinal epithelial cells and the poor solubility of paclitaxel, orally administered paclitaxel has little chance of reaching the bloodstream, thus has very low absolute oral bioavailability. ${ }^{2}$ The reported oral bioavailability values for paclitaxel after intravenous administration of Taxol in rats were in the range of $2.5 \%-6.5 \%,{ }^{4,40,41}$ which is confirmed by our in vivo data (6.39\%). When paclitaxel was loaded into LCNPs and administered orally, $\mathrm{C}_{\max }$ increased from $12.65 \pm 3.52 \mu \mathrm{g} / \mathrm{L}$ (Taxol) to $33.50 \pm 5.46 \mu \mathrm{g} / \mathrm{L}$, and the $\mathrm{AUC}_{(0-24 \mathrm{~h})}$ increased significantly from $82.01 \pm 19.68 \mu \mathrm{g} / \mathrm{L} \cdot \mathrm{h}$ to $169.07 \pm 52.69 \mu \mathrm{g} / \mathrm{L} \cdot \mathrm{h}$. Enhancement of the oral bioavailability of paclitaxel $(13.16 \%$ versus $6.39 \%$ ) might be attributed to encapsulation of paclitaxel inside LCNPs, which would not only help paclitaxel to escape recognition by $\mathrm{P}$-glycoprotein, but would also improve intestinal epithelial permeability by increasing membrane fluidity (Table 1$){ }^{42}$ 


\section{Acknowledgment}

This work was supported by the National Natural Science Foundation of China (81072592, 30801439), the National Key Basic Research Program (2010CB529800), the Innovation Program of Shanghai Municipal Education Commission (12ZZ107), and the Shanghai Science and Technology Committee (10QA1404100, 11430702200). The authors would also like to thank Tessa Nguyen for her help in editing the manuscript.

\section{Disclosure}

The authors report no conflicts of interest in this work.

\section{References}

1. Gursoy RN, Benita S. Self-emulsifying drug delivery systems (SEDDS) for improved oral delivery of lipophilic drugs. Biomed Pharmacother. 2004;58:173-182.

2. Varma MV, Panchagnula R. Enhanced oral paclitaxel absorption with vitamin E-TPGS: effect on solubility and permeability in vitro, in situ and in vivo. Eur J Pharm Sci. 2005;25:445-453.

3. Malingré MM, Meerum Terwogt JM, Beijnen JH, et al. Phase I and pharmacokinetic study of oral paclitaxel. J Clin Oncol. 2000;18: 2468-2475.

4. Gelderblom H, Verweij J, Nooter K, Sparreboom A. Cremophor EL: the drawbacks and advantages of vehicle selection for drug formulation. Eur J Cancer. 2001;37:1590-1598.

5. Yang S, Gursoy RN, Lambert G, Benita S. Enhanced oral absorption of paclitaxel in a novel self-microemulsifying drug delivery system with or without concomitant use of P-glycoprotein inhibitors. Pharm Res 2004;21:261-270.

6. Ma X, Wang H, Jin S, Wu Y, Liang XJ. Construction of paclitaxel-loaded poly (2-hydroxyethyl methacrylate)-g-poly (lactide)-1,2-dipalmitoylsn-glycero-3-phosphoethanolamine copolymer nanoparticle delivery system and evaluation of its anticancer activity. Int $J$ Nanomedicine. 2012;7:1313-1328.

7. Yang D, Van S, Jiang X, Yu L. Novel free paclitaxel-loaded poly(L$\gamma$-glutamylglutamine)-paclitaxel nanoparticles. Int J Nanomedicine. 2011;6:85-91.

8. Roger E, Lagarce F, Garcion E, Benoit JP. Lipid nanocarriers improve paclitaxel transport throughout human intestinal epithelial cells by using vesicle-mediated transcytosis. J Control Release. 2009;140: 174-181.

9. Lee SC, Kim C, Kwon IC, Chung H, Jeong SY. Polymeric micelles of poly(2-ethyl-2-oxazoline)-block-poly( $\varepsilon$-caprolactone) copolymer as a carrier for paclitaxel. J Control Release. 2003;89:437-446.

10. Yaghmur A, Michael R. Liquid crystalline nanoparticles as drug nanocarriers. Available at: http://www.ibr.oeaw.ac.at/people/Michael/ Rappolt_Publ-Dateien/MR2010_5.pdf. Accessed May 31, 2012.

11. Yang D, Armitage B, Marder SR. Minireviews cubic liquid-crystalline nanoparticles. Angew Chem Int Ed Engl. 2004;43:4402-4409.

12. Yaghmur A, Glatter O. Characterization and potential applications of nanostructured aqueous dispersions. Adv Colloid Interface Sci. 2009;147-148:333-342.

13. Efrat R, Aserin A, Kesselman E, Danino D, Wachtel E, Garti N. Liquid micellar discontinuous cubic mesophase from ternary monoolein/ ethanol/water mixtures. Colloids Surf A Physiochem Eng Asp. 2007;299:133-145.

14. Lee KWY, Nguyen TH, Hanley T, Boyd BJ. Nanostructure of liquid crystalline matrix determines in vitro sustained release and in vivo oral absorption kinetics for hydrophilic model drugs. Int J Pharm. 2009;365:190-199.
15. Kaasgaard T, Drummond CJ. Ordered 2-D and 3-D nanostructured amphiphile self-assembly materials stable in excess solvent. Phys Chem Chem Phys. 2006;8:4957-4975.

16. Rosenbaum E, Tavelin S, Johansson LB. A characterisation study on the application of inverted lyotropic phases for subcutaneous drug release. Int J Pharm. 2010;388:52-57.

17. Cervin C, Vandoolaeghe P, Nistor C, Tiberg F, Johnsson M. A combined in vitro and in vivo study on the interactions between somatostatin and lipid-based liquid crystalline drug carriers and bilayers. Eur J Pharm Sci. 2009;36:377-385.

18. Johnsson M, Barauskas J, Norlin A, Tiberg F. Physicochemical and drug delivery aspects of lipid-based liquid crystalline nanoparticles: a case study of intravenously administered propofol. J Nanosci Nanotechnol. 2006;6:3017-3024.

19. Rizwan SB, Assmus D, Boehnke A, et al. Preparation of phytantriol cubosomes by solvent precursor dilution for the delivery of protein vaccines. Eur J Pharm Biopharm. 2011;79:15-22.

20. Lai J, Chen J, Lu Y, et al. Glyceryl monooleate/poloxamer 407 cubic nanoparticles as oral drug delivery systems: I. in vitro evaluation and enhanced oral bioavailability of the poorly water-soluble drug simvastatin. AAPS Pharm Sci Tech. 2009;10:960-966.

21. Batrakova EV, Li S, Vinogradov SV, Alakhov VY, Miller DW, Kabanov AV. Mechanism of Pluronic effect on P-glycoprotein efflux system in blood-brain barrier: contributions of energy depletion and membrane fluidization. J Pharmacol Exp Ther. 2001;99:483-493.

22. Gao X, Wang T, Wu B, et al. Quantum dots for tracking cellular transport of lectin-functionalized nanoparticles. Biochem Biophys Res Commun. 2008;377:35-40.

23. Rizwan SB, Dong YD, Boyd BJ, Rades T, Hook S. Characterisation of bicontinuous cubic liquid crystalline systems of phytantriol and water using cryo field emission scanning electron microscopy (cryo-FESEM). Micron. 2007;38:478-485.

24. Barauskas J, Cervin C, Jankunec M, et al. Interactions of lipid-based liquid crystalline nanoparticles with model and cell membranes. Int $J$ Pharm. 2010;391:284-291.

25. Angelova A, Angelov B, Mutafchieva R, Lesieur S, Couvreur P. Self-assembled multicompartment liquid crystalline lipid carriers for protein, peptide, and nucleic acid drug delivery. Acc Chem Res. 2011;44:147-156.

26. Siekmann B, Bunjes H, Koch MHJ, Westesen K. Preparation and structural investigations of colloidal dispersions prepared from cubic monoglyceride-water phases. Int J Pharm. 2002;244:33-43.

27. Boyd BJ, Khoo SM, Whittaker DV, Davey G, Porter CJH. A lipid-based liquid crystalline matrix that provides sustained release and enhanced oral bioavailability for a model poorly water soluble drug in rats. Int $J$ Pharm. 2007;340:52-60.

28. Boyd BJ. Controlled release from cubic liquid-crystalline particles (cubosomes). In: Lynch ML, Spicer PT, editors. Bicontinuous Liquid Crystals. Boca Raton, FL: CRC Press Inc; 2005.

28. Boyd BJ. Characterisation of drug release from cubosomes using the pressure ultrafiltration method. Int J Pharm. 2003;260:239-247.

30. Garg G, Saraf S, Saraf S. Cubosomes: an overview. Biol Pharm Bull. 2007;30:350-353.

31. Shen H, Crowston JG, Huber F, Saubern S, McLean KM, Hartley PG. The influence of dipalmitoyl phosphatidylserine on phase behaviour of and cellular response to lyotropic liquid crystalline dispersions. Biomaterials. 2010;31:9473-9481.

32. Tenchov BG, MacDonald RC, Siegel DP. Cubic phases in phosphatidylcholine-cholesterol mixtures: cholesterol as membrane "fusogen". Biophys J. 2006;91:2508-2516.

33. Greenspan P, Mayer EP, Fowler SD. Nile red: a selective fluorescent stain for intracellular lipid droplets. J Cell Biol. 1985;10: 965-973.

34. Xiao L, Xiong X, Xiong X, et al. Role of cellular uptake in the reversal of multidrug resistance by PEG-b-PLA polymeric micelles. Biomaterials. 2011;32:5148-5157. 
35. Lamprecht A, Benoit JP. Etoposide nanocarriers suppress glioma cell growth by intracellular drug delivery and simultaneous P-glycoprotein inhibition. J Control Release. 2006;112:208-213.

36. Roger E, Lagarce F, Garcion E, Benoit JP. Reciprocal competition between lipid nanocapsules and P-gp for paclitaxel transport across Caco-2 cells. Eur J Pharm Sci. 2010;40:422-429.

37. Xu P, Gullotti E, Tong L, et al. Intracellular drug delivery by poly (lactic-co-glycolic acid) nanoparticles. Mol Pharm. 2009;6:190-201.

38. Jacobson K, Mouritsen OG, Anderson RGW. Lipid rafts: at a crossroad between cell biology and physics. Nat Cell Biol. 2007;9:7-14.

39. Orlandi PA, Fishman PH. Filipin-dependent inhibition of cholera toxin: evidence for toxin internalization and activation through caveolae-like domains. J Cell Biol. 1998;141:905-915.
40. Garmann D, Warnecke A, Kalayda GV, Kratz F, Jaehde U. Cellular accumulation and cytotoxicity of macromolecular platinum complexes in cisplatin-resistant tumor cells. J Control Release. 2008;131:100-106.

41. Chiu YL, Ho YC, Chen YM, et al. The characteristics, cellular uptake and intracellular trafficking of nanoparticles made of hydrophobicallymodified chitosan. J Control Release. 2010;146:152-159.

42. Xiao L, Xiong X, Xiong X, et al. Role of cellular uptake in the reversal of multidrug resistance by PEG-b-PLA polymeric micelles. Biomaterials. 2011;32:5148-5157.

\section{Publish your work in this journal}

The International Journal of Nanomedicine is an international, peerreviewed journal focusing on the application of nanotechnology in diagnostics, therapeutics, and drug delivery systems throughout the biomedical field. This journal is indexed on PubMed Central, MedLine, CAS, SciSearch $\AA$, Current Contents ${ }^{\circledR} /$ Clinical Medicine,
Journal Citation Reports/Science Edition, EMBase, Scopus and the Elsevier Bibliographic databases. The manuscript management system is completely online and includes a very quick and fair peer-review system, which is all easy to use. Visit http://www.dovepress.com/ testimonials.php to read real quotes from published authors. 